\title{
Pulse oximeter saturation target limits for preterm infants: a survey among European neonatal intensive care units
}

\author{
Maurice J. Huizing ${ }^{1}$ • Eduardo Villamor-Martínez ${ }^{1} \cdot$ Máximo Vento $^{2}$. \\ Eduardo Villamor ${ }^{1}$ (D)
}

Received: 21 June 2016/Revised: 27 October 2016 / Accepted: 31 October 2016/Published online: 16 November 2016

(C) The Author(s) 2016. This article is published with open access at Springerlink.com

\begin{abstract}
The optimum range of pulse oximeter oxygen saturation $\left(\mathrm{SpO}_{2}\right)$ for preterm infants remains controversial. Between November 2015 and February 2016, we conducted a web-based survey aimed to investigate the current and former practices on $\mathrm{SpO}_{2}$ targets in European neonatal intensive care units (NICUs). We obtained valid responses from 193 NICUs, treating 8590 newborns $\leq 28$ weeks per year, across 27 countries. Forty different saturation ranges were reported, ranging from 82-93 to $94-99 \%$. The most frequently utilized $\mathrm{SpO}_{2}$ ranges were 90-95\% (28\%), 88-95\% (12\%), 90-94\% $(5 \%)$, and $91-95 \%(5 \%)$. A total of 156 NICUs $(81 \%)$ changed their $\mathrm{SpO}_{2}$ limits over the last 10 years. The most frequently reported former limits were 88-92\% (18\%), 8595\% (9\%), 88-93 (7\%), and 85-92\% (6\%). The NICUs that increased their $\mathrm{SpO}_{2}$ ranges expected to obtain a reduction in mortality. A 54\% of the NICUs found the scientific evidence supporting their $\mathrm{SpO}_{2}$ targeting policy strong or very strong.
\end{abstract}

Communicated by Patrick Van Reempts

Maurice J. Huizing

m.huizing@mumc.nl

Eduardo Villamor-Martínez

eduardo.villamormartinez@mumc.nl

Máximo Vento

Maximo.Vento@uv.es

Eduardo Villamor

E.Villamor@mumc.nl

1 Department of Pediatrics, Maastricht University Medical Center (MUMC+), P. Debyelaan 25, P.O. Box 5800, 6202

AZ Maastricht, The Netherlands

2 Division of Neonatology, University \& Polytechnic Hospital La Fe, Valencia, Spain
Conclusion: We detected a high degree of heterogeneity in pulse oximeter $\mathrm{SpO}_{2}$ target limits across European NICUs. The currently used limits are 3 to $5 \%$ higher than the former limits, and the most extreme limits, such as lower below $85 \%$ or upper above $96 \%$, have almost been abandoned.

\section{What is Known:}

- For preterm infants requiring supplemental oxygen, the optimum range of pulse oximeter oxygen saturation $\left(\mathrm{SpO}_{2}\right)$ to minimize organ damage, without causing hypoxic injury, remains controversial.

What is New:

- This survey highlights the lack of consensus regarding $\mathrm{SpO}_{2}$ target limits for preterm infants among European neonatal intensive care units (NICUs). We detected 40 different $\mathrm{SpO}_{2}$ ranges, and even the most frequently reported range (i.e., 90-95\%) was used in only $28 \%$ of the 193 respondent NICUs.

- A total of $156 \mathrm{NICUs}(81 \%)$ changed their $\mathrm{SpO}_{2}$ limits over the last 10 years. The currently used limits are 3 to $5 \%$ higher than the former limits, and the most extreme limits, such as lower below $85 \%$ or upper above $96 \%$, have almost been abandoned.

Keywords Oxygen saturation $\cdot$ Preterm $\cdot$ Hypoxia . Hyperoxia

$\begin{array}{ll}\text { Abbreviations } \\ \text { IQR } & \text { Interquartile range } \\ \mathrm{NEC} & \text { Necrotizing enterocolitis } \\ \mathrm{NeOProM} & \begin{array}{l}\text { Neonatal Oxygen Prospective } \\ \text { Meta-analysis }\end{array} \\ \mathrm{NICU} & \begin{array}{l}\text { Neonatal intensive care unit } \\ \mathrm{ROP}\end{array} \\ \mathrm{SpO}_{2} & \text { Retinopathy of prematurity } \\ & \text { Oxygen saturation }\end{array}$




\section{Introduction}

Oxygen is one of the most widely used drugs in the care of (very) preterm infants, and arterial oxygen saturation measured by pulse oximetry $\left(\mathrm{SpO}_{2}\right)$ is the standard, noninvasive, continuous method used to guide oxygen therapy $[6,17,18]$. However, for preterm infants requiring supplemental oxygen, the optimum range of $\mathrm{SpO}_{2}$ to minimize organ damage, without causing hypoxic injury, remains controversial $[9,10]$. Between 2005 and 2007, five randomized trials, known collectively as the Neonatal Oxygen Prospective Meta-analysis (NeOProM) collaboration, were designed to compare the effects of a lower $\mathrm{SpO}_{2}$ target range (85 to $89 \%$ ) vs. a higher target range (91 to $95 \%)$ in preterm infants ( $<28$ weeks) [1, 11]. Combined, these trials suggest that, after postnatal stabilization, the preterm babies assigned to the lower $\mathrm{SpO}_{2}$ target range intention to treat may have increased mortality and necrotizing enterocolitis (NEC), while keeping them in the higher $\mathrm{SpO}_{2}$ range may increase the risk of retinopathy of prematurity (ROP) $[11,18]$. Nevertheless, several neonatologists have raised concerns about potential drawbacks of high $\mathrm{SpO}_{2}$ targets and underlined the high degree of conflicting results of the NeOProM trials $[2,4,7-10,14]$. Additionally, a systematic review and meta-analysis using GRADE criteria concluded that although infants cared for with a higher $\mathrm{SpO}_{2}$ target had significantly lower mortality before hospital discharge, the quality of evidence for this estimate of effect is low [5]. Therefore, in the present climate of uncertainty, one would expect institutional variations on $\mathrm{SpO}_{2}$ targets.

The purpose of this web-based survey was to investigate how $\mathrm{SpO}_{2}$ monitoring policies vary among NICUs in Europe and if the target ranges have been changed in the last years. We also surveyed the expectations of the neonatologists on the effects of changes in $\mathrm{SpO}_{2}$ targets and their opinion on the strength of the presently available evidence.

\section{Methods}

This study received approval from the institutional review board of the Maastricht University Medical Center. Potential responders were informed that participation in the survey was voluntary and that completion of the questionnaire implied consent to participate. European regions differ widely in how they organized the care of preterm infants [16], and to the best of our knowledge, an exhaustive list of European NICUs does not exist [3]. Therefore, in order to obtain the maximal number of responses, we contacted through email a delegate of the national neonatology society of each of the countries mentioned below (see "Results"), requesting them to distribute a web-based survey among the NICUs of their respective country. If no response was obtained after 2 weeks, we contacted another neonatologist of the country. The survey was open between October 2015 and February 2016. The head of the NICU, or a delegated senior neonatologist, was required to fill in the survey, which consisted of the following 10 questions:

1. Please indicate the hospital, city, and country where your NICU is placed.

2. What is your professional position? (head of the NICU/ senior neonatologist)

3. In the last year, approximately how many infants born at $\leq 28$ weeks gestation have been admitted in your NICU?

4. Does your NICU have a written unit policy or guideline for the desired oxygen saturation range for infants born at $\leq 28$ weeks gestation who are receiving oxygen therapy? (Yes/No)

5. In your NICU, in what range do you try to maintain oxygen saturations for infants born at $\leq 28$ weeks gestation who are receiving oxygen therapy?

6. Has your NICU's policy regarding oxygen saturation targeting for infants born at $\leq 28$ weeks gestation been changed in the last 10 years? (Yes/No)

7. If your answer to question 6 was "yes", when were the last changes introduced?

8. If your answer to question 6 was "yes", indicate the numbers that correspond to the former low and high limits of the oxygen saturation range for a 7-day-old infant born at $\leq 28$ weeks gestation receiving oxygen therapy.

9. If your answer to question 6 was "yes", which of the following outcomes do you expect to be reduced with the new saturation targeting policy? (Outcomes were mortality, NEC, bronchopulmonary dysplasia, patent ductus arteriosus, ROP, intraventricular hemorrhage, periventricular leukomalacia, and impaired neurodevelopment. Participants were asked to respond through a scale with 1 indicating very improbable and 5 indicating very probable)

10. In your opinion, how strong is the scientific evidence supporting the beneficial/harmful effects of the oxygen saturation targeting policy that you are currently using in your NICU for infants born at $\leq 28$ weeks gestation? (scale with 1 indicating very weak and 5 indicating very strong).

Only descriptive statistics were performed including frequency counts, percentages, mean and standard deviation as well as median and interquartile range (IQR) when appropriate.

\section{Results}

We received 200 responses from European NICUs, of which 193 were valid for analysis. Due to the method of distribution and the absence of an exhaustive list of European NICUs [3, 
16], it was not possible to obtain complete data on the number of NICUs that received the survey. Some of the contacted neonatologists distributed the survey in their country but did not notify us of the number of NICUs that were contacted. Therefore, a response rate could not be determined. The 193 respondent NICUs treated 8590 infants aged $\leq 28$ weeks in the last year (median 40, IQR 22-55). The distribution of responses per country was the following: Belgium 9, Bosnia and Herzegovina 1, Bulgaria 1, Czech Republic 3, Denmark 3, Finland 3, France 15, Germany 25, Greece 4, Hungary 6, Iceland 1, Ireland 3, Italy 16, Latvia 1, Norway 1, Portugal 4, Poland 1, Russia 18, Serbia 3, Slovakia 3, Slovenia 1, Spain 27, Sweden 13, Switzerland 6, the Netherlands 9, Turkey 12, and UK 3. No response was obtained from Austria, Cyprus, Estonia, Georgia, Lithuania, Macedonia, Malta, Romania, and Ukraine. The head of the NICU responded the survey in $70 \%$ of the cases.

A total of 140 NICUs (73\%) reported to have a written policy or guideline on oxygen saturation limits. The limits currently used in the 193 NICUs are depicted in Table 1. Limits were combined in 40 different ranges. The four most frequently used ranges were 90-95, 88-95, 90-94, and 9195\% (Fig. 1). The distribution of the ranges across the countries with more than five respondents is shown in Table 2. From the 193 respondent NICUs, 156 (81\%) changed their oxygen saturation limits in the last 10 years ( 9 changed less than 1 year ago, 29 changed 1 year ago, 48 changed 2 years ago, 24 changed 3 years ago, 13 changed 4 years ago, 16 changed 5 years ago, 16 changed more than 5 years ago, and 1 did not answer). The limits formerly used in these 156 NICUs are depicted in Table 1 and the ranges in Fig. 2. Table 3 shows the direction of the changes in $\mathrm{SpO}_{2}$ ranges. The expectations on the effect of the changes on outcome are shown in Fig. 3. For analysis of this question, responses were divided into three groups: (1) NICUs using a lower limit of 86-88\% and an upper limit $\leq 94 \%(n=22),(2)$ NICUs using a range of 88-95\% $(n=19)$, (3) NICUs using a lower limit of $90-91 \%$ and an upper limit of $95 \%(n=55)$. The evidence supporting the beneficial/harmful effects of their current saturation targeting policy was considered strong or very strong by $54 \%$ of the respondents, neutral by $30 \%$, and weak or very weak by $15 \%$. The consideration on the strength of the evidence within the above three groups is depicted in Fig. 3d.

\section{Discussion}

This survey highlights the lack of consensus regarding $\mathrm{SpO}_{2}$ target limits for preterm infants among European neonatologists. We detected 40 different $\mathrm{SpO}_{2}$ ranges and even the most frequently reported range (i.e., 90-95\%) was used in only $28 \%$ of the respondent NICUs. The heterogeneity in $\mathrm{SpO}_{2}$ target ranges was also a general observation within countries,
Table 1 Current and former $\mathrm{SpO}_{2}$ limits used in European NICUs for infants of gestational age $\leq 28$ weeks

\begin{tabular}{|c|c|c|}
\hline & \multicolumn{2}{|l|}{ Number of centers } \\
\hline & Current $(n=193), n(\%)$ & Former $(n=156), n(\%)$ \\
\hline \multicolumn{3}{|c|}{ Lower limit } \\
\hline 80 & & $4(2)$ \\
\hline 82 & $1(1)$ & $2(1)$ \\
\hline 83 & $1(1)$ & $4(2)$ \\
\hline 84 & & $3(2)$ \\
\hline 85 & $12(8)$ & $53(27)$ \\
\hline 86 & $5(3)$ & $10(5)$ \\
\hline 87 & $5(3)$ & $9(5)$ \\
\hline 88 & $33(21)$ & $65(34)$ \\
\hline 89 & $9(6)$ & $3(2)$ \\
\hline 90 & $70(45)$ & $20(10)$ \\
\hline 91 & $10(6)$ & $2(1)$ \\
\hline 92 & $7(5)$ & $8(4)$ \\
\hline 93 & & $2(1)$ \\
\hline 94 & $1(1)$ & $3(2)$ \\
\hline 95 & & $5(3)$ \\
\hline \multicolumn{3}{|c|}{ Upper limit } \\
\hline 87 & & $1(1)$ \\
\hline 88 & & $1(1)$ \\
\hline 89 & & $3(2)$ \\
\hline 90 & $1(1)$ & $9(5)$ \\
\hline 92 & $8(5)$ & $53(27)$ \\
\hline 93 & $18(12)$ & $31(16)$ \\
\hline 94 & $21(14)$ & $9(5)$ \\
\hline 95 & $92(60)$ & $47(24)$ \\
\hline 96 & $11(7)$ & $8(4)$ \\
\hline 97 & $2(1)$ & $6(3)$ \\
\hline 98 & & $14(7)$ \\
\hline 99 & $1(1)$ & $6(3)$ \\
\hline 100 & & $5(3)$ \\
\hline
\end{tabular}

The former limits refer to the limits previously utilized by the 156 NICUs that changed their limits in the last 10 years

since only in two cases (Turkey and Hungary) the same range was used by more than $50 \%$ of the NICUs of the same country. A similar degree of variability in $\mathrm{SpO}_{2}$ targets has been recently reported among the NICUs of the UK [12]. Although the method used for the distribution of our survey does not allow us to calculate a response rate, we obtained numerous responses of the majority of European countries, including the largest NICUs. Other surveys on European NICUs reported a number of responses similar to the one obtained by us [3]. Therefore, we believe the present results are representative of current management practices in Europe.

An $81 \%$ of the NICUs reported a recent change in their policy of $\mathrm{SpO}_{2}$ target limit. Despite the variability, two 


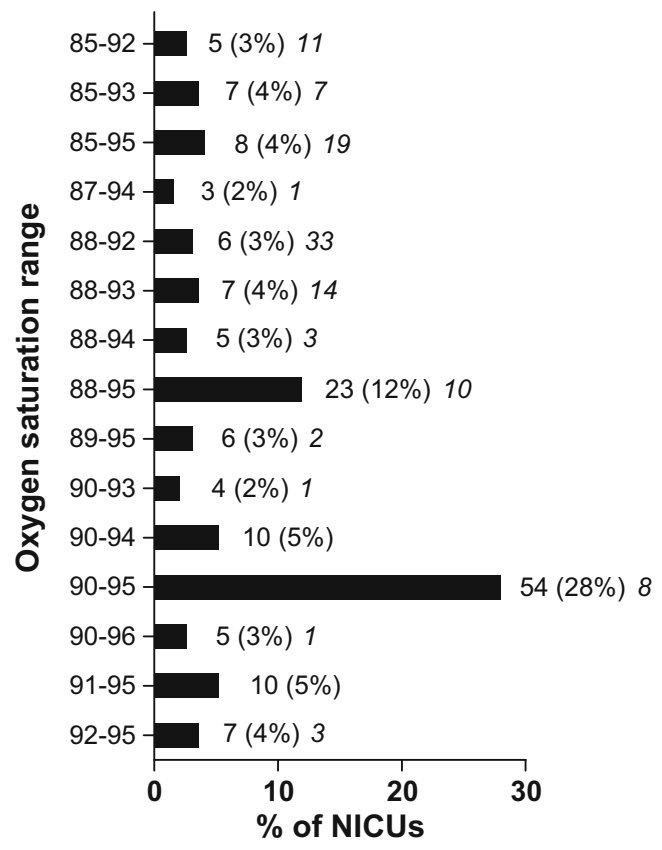

Fig. 1 Current $\mathrm{SpO}_{2}$ ranges used in 193 European NICUs. Results are expressed as $n(\%)$. The number in italic indicates the number of NICUs having the same range over the last 10 years. For clarity, ranges reported by only one or two NICUs are not shown in the figure. Limits used in only one center are 82-93, 85-97, 86-93, 86-94. 86-95, 86-96, 87-92, 8897, 89-92, 89-96, 90-92, 90-97, 90-98, 91-96, 92-94, 93-98, and 94 99. Limits used in two centers are 83-93, 85-90, 86-92, 87-93, 87-95, 88-96, 89-94, and 95-96

consequences of these changes can be identified. First, the currently used limits are 3 to $5 \%$ higher than the former limits. Consequently, it would be wise to scrutinize the incidence in conditions associated with hyperoxia such as ROP in the coming years. Second, the most extreme limits, such as lower below $85 \%$ or upper above $96 \%$, have almost been abandoned. Taken together, these changes may reflect the impact of the evidence generated by the NeOProM trials on clinical

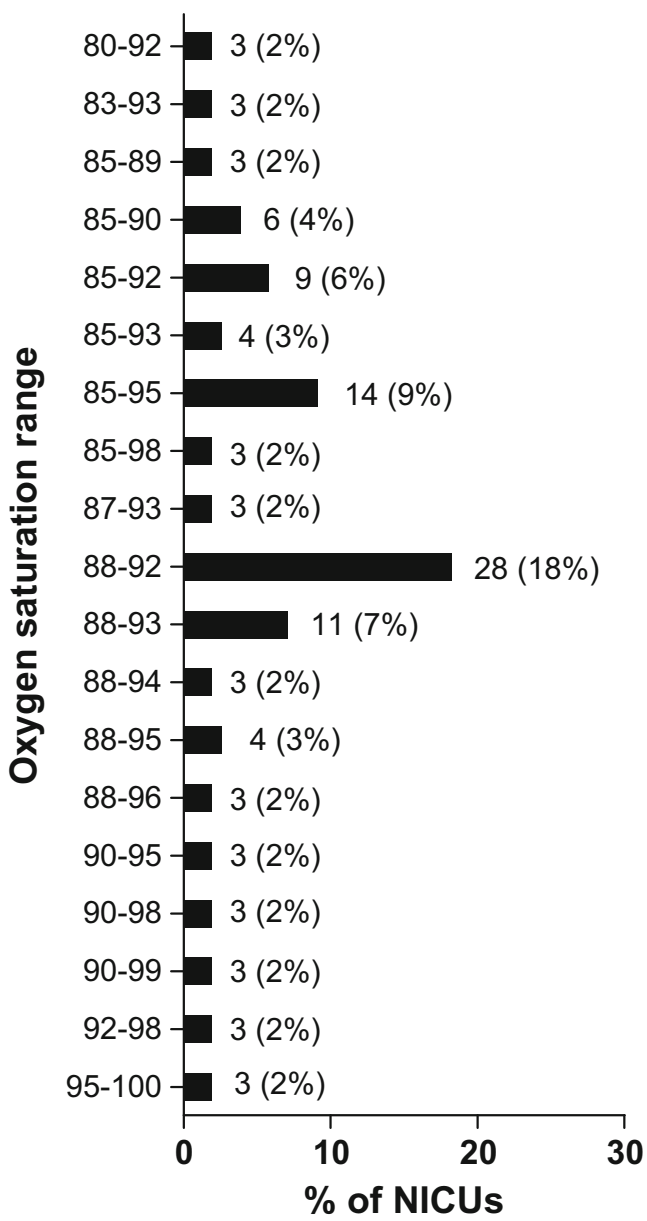

Fig. 2 Former $\mathrm{SpO}_{2}$ ranges used in 156 European NICUs that changed their limits in the last 10 years. Results are expressed as $n(\%)$. For clarity, ranges reported by only one or two NICUs are not shown in the figure. Limits used in only one center are 80-87, 84-92, 84-94, 84-96, 85-88, 86-96, 87-95, 88-97, 88-98, 89-95, 89-97, 90-96, 91-100, 92-95, 9297, 92-99, 93-97, 94-96, 94-98, 94-99, 95-98, 95-99, 92-97, 92-95, 90-100, and 91-100. Limits used in two centers are 80-95, 82-92, 8594, 86-95, 86-90, 86-93, 86-94, 87-92, and 90-97

Table 2 Distribution of $\mathrm{SpO}_{2}$ targeting limit ranges per country

\begin{tabular}{|c|c|c|c|c|c|}
\hline \multirow[t]{2}{*}{ Country (respondents) } & \multirow{2}{*}{$\begin{array}{l}\text { Centers that } \\
\text { changed, } n(\%)\end{array}$} & \multirow{2}{*}{$\begin{array}{l}\text { Number } \\
\text { of ranges }\end{array}$} & \multicolumn{3}{|c|}{ Most frequent ranges (\%) } \\
\hline & & & First & Second & Third \\
\hline Spain $(n=27)$ & $24(89)$ & 12 & $90-95$ (44) & $88-95(15)$ & $90-94(7)$ \\
\hline Germany $(n=25)$ & $16(64)$ & 12 & $90-95(20)$ & $85-95(16)$ & $85-93(12)$ \\
\hline Russia $(n=18)$ & $17(94)$ & 13 & $90-95(28)$ & $92-95(11)$ & \\
\hline Italy $(n=16)$ & $9(56)$ & 12 & 88-95 (19) & $90-95(13)$ & 87-94 (13) \\
\hline France $(n=15)$ & $12(80)$ & 9 & $88-95(33)$ & $92-95(13)$ & $89-95(13)$ \\
\hline Sweden $(n=13)$ & $10(77)$ & 6 & $90-94(23)$ & $90-95(23)$ & $91-95(23)$ \\
\hline Turkey $(n=12)$ & $9(75)$ & 5 & $90-95$ (67) & & \\
\hline Netherlands $(n=9)$ & $9(100)$ & 7 & $90-95(22)$ & $91-95(22)$ & \\
\hline Belgium $(n=9)$ & $7(78)$ & 8 & $88-95(22)$ & & \\
\hline Hungary $(n=6)$ & $6(100)$ & 3 & $90-95(67)$ & & \\
\hline Switzerland $(n=6)$ & $4(67)$ & 5 & $85-92(33)$ & & \\
\hline
\end{tabular}


Table 3 Changes in $\mathrm{SpO}_{2}$ targeting limits introduced in European NICUs in the last 10 years

\begin{tabular}{|c|c|c|c|}
\hline \multirow[t]{2}{*}{ Lower limit } & \multicolumn{3}{|l|}{ Upper limit } \\
\hline & Increased & Maintained & Decreased \\
\hline \multirow[t]{3}{*}{ Increased } & $n=77(40 \%)$ & $n=28(15 \%)$ & $n=13(7 \%)$ \\
\hline & L: 90 (85-92) & L: 90 (85-92) & L: 88 (86-94) \\
\hline & U: 95 (92-97) & U: 95 (92-96) & U: 95 (92-99) \\
\hline \multirow[t]{3}{*}{ Maintained } & $n=3(2 \%)$ & $n=37(23 \%)$ & $n=4(2 \%)$ \\
\hline & L: 88 (85-88) & L: 88 (83-93) & L: 90 (88-90) \\
\hline & U: 95 (90-96) & U: 95 (90-98) & U: 95 (92-96) \\
\hline \multirow[t]{3}{*}{ Decreased } & 0 & $n=1(1 \%)$ & $n=30(16 \%)$ \\
\hline & & L: 85 & L: 88 (82-92) \\
\hline & & U: 93 & U: 94.5 (92-97) \\
\hline
\end{tabular}

$n=$ number of centers $(\%)$. The number after $\mathrm{L}$ and $\mathrm{U}$ represents the median (range) of the current $\mathrm{SpO}_{2}$ targeting limit. For example, 77 centers have increased both the lower and the upper $\mathrm{SpO}_{2}$ targeting limit in the last 10 years. These 77 centers currently used a median lower limit of 90\% (range 85-92) and a median upper limit of 95\% (range 92-97)

$L$ lower limit, $U$ upper limit

practice. It has been argued that, at present, the most rigorously evaluated evidence is that targeting a $\mathrm{SpO}_{2}$ of 91 to $95 \%$ is safer than targeting a $\mathrm{SpO}_{2}$ of 85 to $89 \%[11,15]$. In 2013, a European panel of experts, convened under the auspices of the European Association of Perinatal Medicine to update evidence-based guidelines on the management of neonatal respiratory distress syndrome, recommended a saturation range of 90-95\% [13]. Our survey shows that this recommendation is followed by only $28 \%$ of the respondent NICUs. Moreover, the NeOProM higher target of $91-95 \%$ has been adopted by only $5 \%$ of the NICUs. In general, the NICUs that changed their range to $90-95$ or $91-95 \%$ expect to obtain a reduction in mortality and, to a lesser extent, a reduction in neurodevelopmental impairment and NEC.

A number of neonatologists consider that the NeOProM upper limits may result in partial pressures of oxygen above the physiologic limits given the characteristics of the hemoglobin oxygen saturation curve $[9,10]$. They suggest that it is safer to widen the target, using $\mathrm{SpO}_{2}$ ranges like 86-93, 87-94, or 88$94 \%[9,10]$. Our survey shows that these intermediate targets are currently used by $14 \%$ of the respondent NICUs. It is noteworthy that $45 \%$ of the NICUs that changed to intermediate saturation targets also consider achieving a reduction in mortality probable or very probable. Finally, a $12 \%$ of the respondent NICUs are using a wider $\mathrm{SpO}_{2}$ range of 88-95\%. Their expectations are similar than the ones reported by the NICUs using the higher limits. Interestingly, independently of their choice of saturation targets, more than $50 \%$ of the respondents consider the evidence supporting their choice as strong or very strong.

In conclusion, a definitive answer to the optimal $\mathrm{SpO}_{2}$ level for preterm neonates is still elusive. This is reflected in a wide
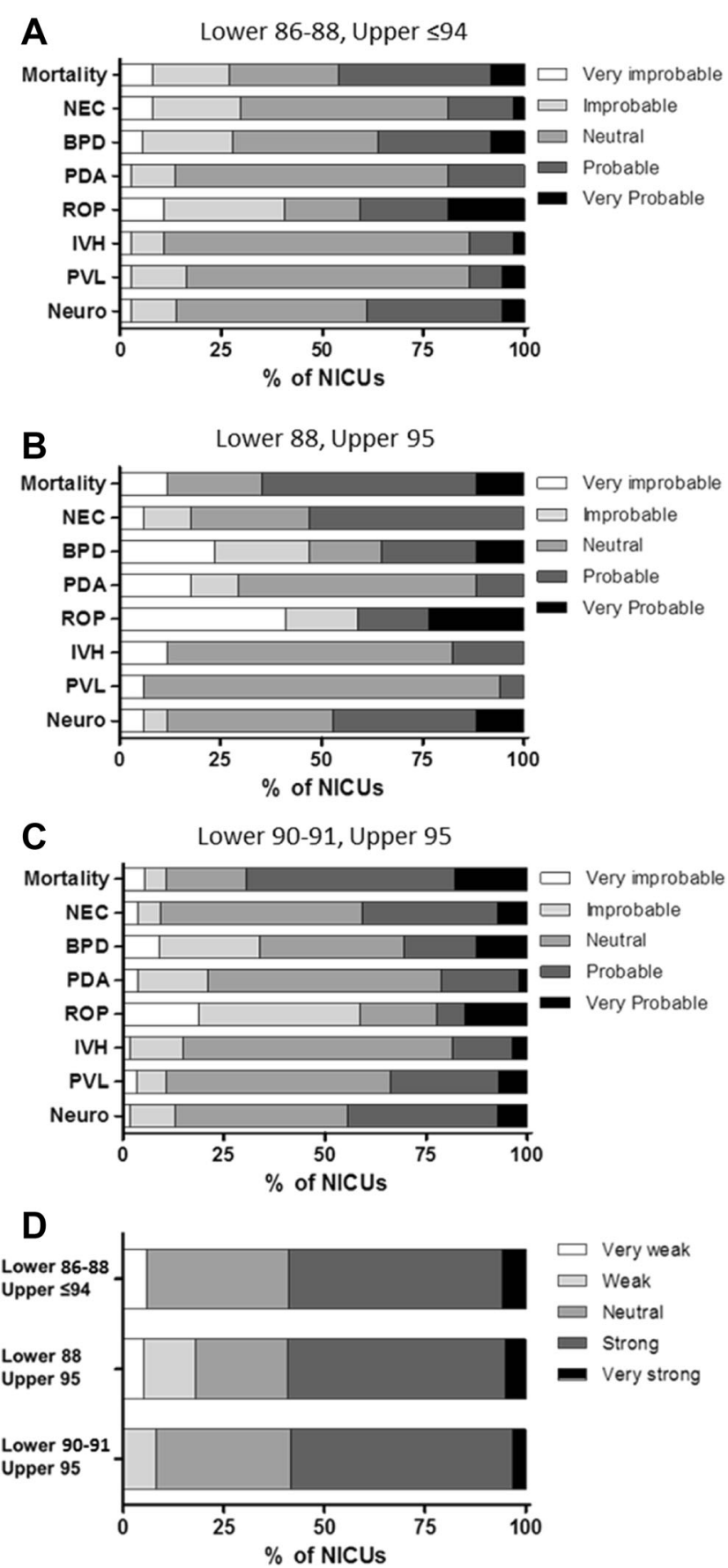

Fig. 3 a-c Expected reduction in adverse outcomes after changes in $\mathrm{SpO}_{2}$ ranges. The following question was posed: Which of the following outcomes do you expect to be reduced with the new saturation targeting policy? Participants were asked to respond through a scale with 1 indicating very improbable and 5 indicating very probable. For analysis of this question, responses were divided into three groups: a NICUs using a lower limit of 86-88\% and an upper limit $\leq 94 \%(n=22)$, b NICUs using a range of $88-95 \%(n=19)$, and $\mathbf{c}$ NICUs using a lower limit of $90-91 \%$ and an upper limit of $95 \%(n=55)$. Neuro neurodevelopmental impairment. d Opinion on the strength of scientific evidence. The following question was posed: In your opinion, how strong is the scientific evidence supporting the beneficial/harmful effects of the oxygen saturation targeting policy that you are currently using in your NICU for infants born at $\leq 28$ weeks gestation? (scale with 1 indicating very weak and 5 indicating very strong) 
variation of unit policies on $\mathrm{SpO}_{2}$ targets across Europe and highlights the necessity of further investigation. Moreover, since all five $\mathrm{NeOProM}$ trials used a similar study design, a prospective meta-analysis is planned when follow-up of study infants has occurred in the last trial [1]. Hopefully this metaanalysis will help to find the best evidence-based $\mathrm{SpO}_{2}$ targets.

\section{Acknowledgments}

Authors' contributions MJH participated in the design of the study; collection, analysis, and interpretation of the data; and draft of the manuscript. EV-M participated in the collection, analysis, and interpretation of the data, and draft of the manuscript. MV participated in the design of the study, analysis and interpretation of the data, and draft of the manuscript. EV conceived and designed the study and participated in the collection, analysis, and interpretation of the data, and draft of the manuscript. All authors read and approved the final manuscript.

\section{Compliance with ethical standards}

Conflict of interest The authors declare that they have no conflict of interest.

Ethical approval All procedures performed in studies involving human participants were in accordance with the ethical standards of the institutional and/or national research committee and with the 1964 Helsinki Declaration and its later amendments or comparable ethical standards.

\section{Funding None declared.}

Open Access This article is distributed under the terms of the Creative Commons Attribution 4.0 International License (http:// creativecommons.org/licenses/by/4.0/), which permits unrestricted use, distribution, and reproduction in any medium, provided you give appropriate credit to the original author(s) and the source, provide a link to the Creative Commons license, and indicate if changes were made.

\section{References}

1. Askie LM, Brocklehurst P, Darlow BA, Finer N, Schmidt B, Tarnow-Mordi W (2011) NeOProM: Ne onatal O xygenation Pro spective M eta-analysis Collaboration study protocol. BMC Pediatr $11: 1$

2. Jobe AH (2014) Oxygen saturation targeting - an illusion. J Pediatr 164:679-68

3. Kaguelidou F, Pandolfini C, Manzoni P, Choonara I, Bonati M, Jacqz-Aigrain E (2012) European survey on the use of prophylactic fluconazole in neonatal intensive care units. Eur J Pediatr 171:439-445
4. Lakshminrusimha S, Manja V, Mathew B, Suresh G (2015) Oxygen targeting in preterm infants: a physiological interpretation. $\mathrm{J}$ Perinatol 35:8-15

5. Manja V, Lakshminrusimha S, Cook DJ (2015) Oxygen saturation target range for extremely preterm infants: a systematic review and meta-analysis. JAMA Pediatr 169:332-340

6. Nghiem TH, Hagadorn JI, Terrin N, Syke S, MacKinnon B, Cole CH (2008) Nurse opinions and pulse oximeter saturation target limits for preterm infants. Pediatrics 121:e1039e1046

7. Samiee-Zafarghandy S, Saugstad OD, Fusch C (2015) Do we have an answer when it comes to providing extremely preterm infants with optimal target oxygen saturation? Acta Paediatr 104:e130 e133

8. Schmidt B, Whyte RK, Roberts RS (2014) Trade-off between lower or higher oxygen saturations for extremely preterm infants: the first benefits of oxygen saturation targeting (BOOST) II trial reports its primary outcome. J Pediatr 165:6-8

9. Sola A (2015) Oxygen saturation in the newborn and the importance of avoiding hyperoxia-induced damage. NeoReviews 16: e393-e405

10. Sola A, Golombek SG, Montes Bueno MT, Lemus-Varela L, Zuluaga C, Dominguez F, Baquero H, Young Sarmiento AE, Natta D, Rodriguez Perez JM, Deulofeut R, Quiroga A, Flores GL, Morgues M, Perez AG, Van Overmeire B, van Bel F (2014) Safe oxygen saturation targeting and monitoring in preterm infants: can we avoid hypoxia and hyperoxia? Acta Paediatr 103:10091018

11. Stenson BJ (2016) Oxygen saturation targets for extremely preterm infants after the NeOProM trials. Neonatology 109: 352-358

12. Sutton R, Raptaki M, Wilby E, Mahaveer A (2014) Oxygen saturation target monitoring in preterm babies: a survey of level 3 units in United Kingdom. Arch Dis Child 99:A53

13. Sweet DG, Carnielli V, Greisen G, Hallman M, Ozek E, Plavka R, Saugstad OD, Simeoni U, Speer CP, Vento M (2013) European consensus guidelines on the management of neonatal respiratory distress syndrome in preterm infants - 2013 update. Neonatology 103:353-368

14. Synnes A, Miller SP (2015) Oxygen therapy for preterm neonates: the elusive optimal target. JAMA Pediatr 169:311-313

15. Tarnow-Mordi W, Stenson B, Kirby A, Juszczak E, Donoghoe M, Deshpande S, Morley C, King A, Doyle LW, Fleck BW (2016) Outcomes of two trials of oxygen-saturation targets in preterm infants. New Engl J Med 374:749-760

16. Van Reempts P, Gortner L, Milligan D, Cuttini M, Petrou S, Agostino R, Field D, den Ouden L, Børch K, Mazela J (2007) Characteristics of neonatal units that care for very preterm infants in Europe: results from the MOSAIC study. Pediatrics 120:e815e825

17. Van Zanten HA, Tan RN, van den Hoogen A, Lopriore E, te Pas AB (2015) Compliance in oxygen saturation targeting in preterm infants: a systematic review. Eur J Pediatr 174: $1561-1572$

18. Vento M (2014) Oxygen supplementation in the neonatal period: changing the paradigm. Neonatology 105:323-331 